\section{Two cases of monoclonal nodular pulmonary amyloidosis and review of the literature}

\author{
Kendal M. Endicott, ${ }^{1}$ Conor F. Hynes, ${ }^{1}$ \\ Cindy M. Hsieh, ${ }^{2}$ Edina Paal, 2,3 \\ Gregory Trachiotis ${ }^{1,4}$ \\ 1 Division of Cardiothoracic Surgery, \\ Veterans Affairs Medical Center, \\ Washington, DC; ${ }^{2}$ Department of \\ Pathology, The George Washington \\ University, Washington, DC; ${ }^{3}$ Pathology \\ and Laboratory Medicine Service, \\ Veterans Affairs Medical Center, \\ Washington, DC; ${ }^{4}$ Division of \\ Cardiothoracic Surgery, The George \\ Washington University, Washington, DC, \\ USA
}

\begin{abstract}
Nodular pulmonary amyloidosis (NPA) is an uncommon pathology of insoluble protein depositing in pulmonary parenchyma. This localized pulmonary form of amyloidosis is most often found to contain combinations of kappa and lambda immunoglobulin light chain and immunoglobulin heavy chain proteins with a polyclonal lymphoplasmacystic infiltrate. Herein we present two cases of NPA of the rarely reported monoclonal (light-chain restricted) form with review of the literature and discussion of the clinical, radiographic, and histologic features of NPA.
\end{abstract}

\section{Introduction}

Amyloidosis is a disease that results from tissue deposition of abnormally folded protein. To date, more than 30 different types of amyloid have been described, which all share the morphologic characteristics of fibrillar betapleated sheet configuration. ${ }^{1}$ The most common type of amyloid is derived from immunoglobulin light chain (AL) and usually presents as a systemic disease, commonly involving the kidneys, liver and spleen. ${ }^{2}$ Localized amyloid deposition can be organ specific where amyloid precursor is normally produced by the organ, or amyloid (most frequently AL amyloid) may deposit in a non-specific localized form, confined to a specific organ system. ${ }^{3}$ Amyloidosis involving the lung can be divided broadly into cases associated with systemic amyloidosis or those restricted to localized pulmonary anatomy.

Localized pulmonary forms are most often found to contain of kappa or lambda AL.
Histologically, three main subtypes have been described including tracheobronchial, diffuse alveolar septal amyloidosis, and nodular pulmonary (NPA). ${ }^{4}$ Of these types, NPA and tracheobronchial are typically confined to the lung with NPA being the most common form accounting for about half of reported cases. NPA is typically of the AL type and can be associated with a polyclonal lymphoplasmacystic infiltrate, though rare monoclonal types with multiple lesions have been reported..$^{5-10}$

Herein we report two clinical cases of monoclonal nodular pulmonary amyloidosis including one with a previously unreported presentation of a single, dominant lesion in addition to a review of the literature.

\section{Case Report}

\section{Case \#1}

A 55 year-old male with a chronic non-productive cough and 20 pack-year smoking history was referred to the surgical service with CT finding of a $1.4 \mathrm{~cm}$ spiculated nodule in the right middle lobe of his lung adjacent to the visceral pleura. PET scan showed moderate avidity with SUV of 4.2. CT-guided percutaneous lung biopsy revealed non-diagnostic aspirate of rare atypical cells. Physical exam revealed no neurologic dysfunction. Liver function tests and creatinine clearance were normal. Cardiac MRI demonstrated an interventricular septum (IVS) of $8 \mathrm{~mm}$, ejection fraction (EF) of $75 \%$, and normal left ventricular (LV) mass for age and gender $\left(56.2 \mathrm{~g} / \mathrm{m}^{2}\right)$. There was also no evidence of late gadolinium enhancement to suggest cardiac amyloid.

Thoracoscopic wedge biopsy and mediastinal lymph node dissection were obtained which identified a $2.2 \mathrm{~cm}$ lesion consistent with a localized pulmonary amyloidoma. The wedge resection demonstrated a firm, homogenous dry grey-white mass puckering the pleura $(2.2 \times 1.5 \times 1.0 \mathrm{~cm})$. Histologically, the lesion was a circumscribed nodule with acellular, amorphous eosinophilic material filling the alveolar spaces and foci of osteoid metaplasia. Multinucleated giant cells and a mature appearing lymphoplasmacytic infiltrate were present, most notably at the edge of the lesion. On Congo-Red stain, the material had a salmon-colored appearance which showed apple-green birefringence under polarized light. Immunohistochemical stains revealed lambda light chain restriction of the plasma cells (Figure 1). The final diagnosis was pulmonary amyloidoma with osteoid metaplasia. Mediastinal lymph nodes showed no significant histopathologic abnormality.

Serum protein electrophoresis showed hypoalbuminemia but was otherwise unre-
Correspondence: Gregory Trachiotis, Division of Cardiothoracic Surgery, Veterans Affairs Medical Center, Washington, DC, USA

Tel: +1.202.745.6075.

E-mail: gregory.trachiotis@va.gov

Key words: Pulmonary nodule; Amyloidosis; Immunoglobulin.

Contributions: EKM, analysis and interpretation of data, drafting of manuscript, critical revision, final approval of manuscript; HCF, study conception and design, acquisition of data, analysis and interpretation of data, drafting of manuscript, approval of manuscript; HCM, acquisition of data, analysis and interpretation of data, approval of manuscript; PE, study conception and design, analysis and interpretation of data, drafting of manuscript, critical revision, approval of manuscript; TG, study conception and design, analysis and interpretation of data, drafting of manuscript, critical revision, approval of manuscript.

Conflicts of interest: the authors declare no potential conflict of interest.

Received for publication: 18 April 2016.

Revision received: 17 June 2016

Accepted for publication: 28 June 2016.

This work is licensed under a Creative Commons Attribution NonCommercial 4.0 License (CC BYNC 4.0).

(C) Copyright K.M. Endicott et al., 2016

Licensee PAGEPress, Italy

Chest Disease Reports 2016; 4:5945

doi:10.4081/cdr.2016.5945

markable. Urine protein electrophoresis was normal. Repeat serum protein electrophoresis was essentially normal with no evidence of monoclonal gammopathy. Serum free lambda light chains were within normal limits. Free kappa light chains were slightly elevated but the kappa to lambda ratio was within the reference range. AA amyloid was negative by immunostain. Abdominal fat pad aspirate was performed to rule out systemic amyloidosis with negative result. Of note, only Kappa and Lambda antibodies are available in our laboratory. These immunostains were done to demonstrate clonality of the surrounding plasmacytic infiltrates. Because of the high background, use of these antibodies is limited to characterize the nature of the amyloid.

\section{Case \#2}

A 76 year-old male presented with severe aortic valve stenosis with symptoms of dyspnea on mild exertion and ostial LAD stenosis confirmed by cardiac catheterization. At this time, he was known to have bilateral pulmonary nodules in all lung lobes. By CT imaging, these were suspicious for nodular pulmonary amyloi- 
dosis given their shape, pattern of calcification, and stability in size. Echocardiogram found preserved LVEF of $55 \%$ and no visualized myocardial deposits. The IVS measured at 0.98 $\mathrm{cm}$ with no evidence of diastolic function. Pulmonary function testing was normal, and the patient had no history of smoking.

Repeat CT scan of the chest without contrast revealed multiple bilateral lung nodules in all lung lobes with irregular calcifications with associated septal thickening suggestive of amyloid infiltration. Bilateral hilar and mediastinal lymphadenopathy were slightly increased in size from previous CT a year prior, however, lung nodules were unchanged. PET scan showed these lesions to have standardized uptake values ranging from 2.3-5.8 SUV. In addition, there was radiotracer uptake in bilateral paratracheal, hilar, prevascular, and subcarinal lymph nodes ranging from 3.64.5 SUV.

Transbronchial biopsies of bilateral hilar lymph nodes as well as right upper and middle lobe masses were non-diagnostic, thus left upper lobe wedge resection was performed at the time of aortic valve replacement and coronary artery bypass grafting. Histology was consistent with amyloidosis. The lung parenchyma contained yellow brittle nodules with gross central calcification. Light microscopy identified a deposit of eosinophilic homogenous material with giant cell foreign body reaction on hematoxylin and eosin stain. Congo Red staining under polarized light revealed apple-

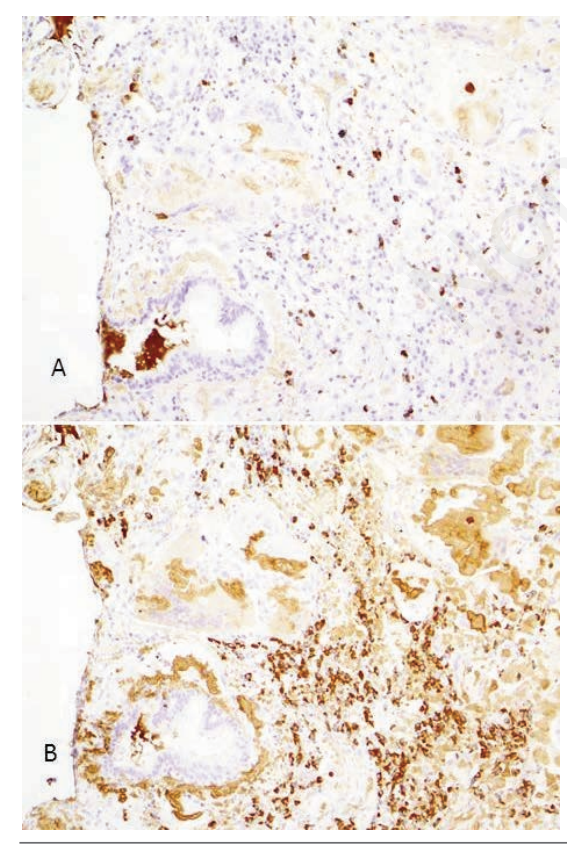

Figure 1. Immunohistochemistry for kappa (A) and lambda (B) light chains reveals lambda light change restriction of the plasma cells (original magnifications $\mathrm{x} 200$ ). green birefringence confirming the presence of amyloid. Immunohistochemistry showed CD138+ plasma cell infiltration with kappa/lambda light chain antibodies binding at a kappa restricted ratio of 100:1, indicating a monoclonal population. On serum protein electrophoresis, the patient was found to have a faint monoclonal band. Serum and urine free light chains were minimal and within a normal ratio. Bone marrow biopsy demonstrated an atypical plasma cell infiltrate (8\% plasma cells), however it did not meet criteria for plasma cell dyscrasia. Bone marrow biopsy also showed no evidence of amyloid. These findings granted the diagnosis of monoclonal gammopathy of undetermined significance.

\section{Discussion}

Amyloidosis can be particularly difficult to diagnose because workup involves imaging, blood, and urine studies - none of which alone are diagnostic. Proper assessment of the amyloid involves typing the protein deposits by immunohistochemical (IHC) staining, immunogold electron microscopy, or mass spectrometry. ${ }^{11}$ Typing of the amyloid is ideal but is available only in highly specialized institutions. Congo red stain confirms the presence of amyloid. Staining for lambda and kappa light chains to assess clonality should be done, but clonality is not necessarily associated with systemic disease. Serum and urine protein analysis is necessary to exclude an underlying or concurrent amyloid producing plasma cell dyscrasia or lymphoma. Plasma cell dyscrasia work up includes serum protein electrophoresis, serum free light chain assays, serum and urine immunofixation electrophoreses, and bone marrow biopsy with flow cytometry. In addition, of particular concern is the assessment for systemic disease resulting in major end organ damage (i.e. cardiac, liver, kidney, or nervous system dysfunction.) Assessment of cardiac function by echocardiography, scintigraphy, or magnetic resonance has become standard as cardiac involvement is the major determinant of long-term outcomes. While amyloidosis is seen with some frequency in clinical practice, NPA is less common. Particularly of the popyclonal type, approximately one hundred cases have been reported in the literature of NPA (Table 1)., ${ }^{3,5-17}$ NPA is typically of the AL variant, specifically lambda light chain despite the usual association of AL amyloid with systemic amyloidosis..$^{2-4,15}$ The amyloid is speculated to arise from a reaction to chronic inflammatory conditions of the lung, including connective tissue disorders, tuberculosis, or HIV infection. In keeping with this presumptive origin, pulmonary amyloidoma is thus usually associated with a polyclonal lymphoplasmacytic infiltrate at its periphery. ${ }^{15}$ Nine cases, including our two recent cases, have been reported of otherwise histologically typical pulmonary amyloidomas being associated with a monoclonal lymphoplasmacytic infiltrate..$^{18-23}$ Of these cases, age ranges from 55 to 73 with male predominance (7 of 9 cases). All cases demonstrated multifocal lesions with the exception of our new case presentation (Case 1). The relevant information from these cases is listed in Table 2. Given the rarity of this pathologic type, its significance is not well understood.

Nodular pulmonary amyloidoma with associated monoclonal plasmacytic infiltrate, a localized amyloid, is thus a rare entity. It is radiographically and morphologically identical to nodular pulmonary amyloidoma without light

Table 1. Reported cases of pulmonary amyloidoma with associated polyclonal lymphoplasmacytic reaction.

\begin{tabular}{lcccc} 
Reference & Average age (range) & Sex (M:F) & Size (cm) & Number of cases \\
Hui & 64 & NR & $1-4$ & 28 \\
Thompson & NR & NR & $1-15$ & 55 \\
\hline da Costa & $49(28-59)$ & $3: 3$ & $2-7$ & 6 \\
Pitz & 48 & $1: 0$ & NR & 1 \\
\hline Utz & $67(43-78)$ & NR & NR & 7 \\
Smith & $79(74-87)$ & $2: 1$ & $.5-2$ & 3 \\
\hline Cordier & NR & $2: 0$ & $1-3.5$ & 2 \\
Dacic & $55(25-65)$ & $3: 3$ & NR & 6 \\
\hline Kawashima & 75 & $0: 1$ & NR & 1 \\
Podbielski & 65 & $0: 1$ & 2 & 1 \\
\hline Desai & $59(48-69)$ & $1: 1$ & NR & 1 \\
Pusztaszeri & 72 & $0: 1$ & 5 & 1 \\
\hline Asad & 72 & $0: 1$ & NR & 1 \\
\hline
\end{tabular}

$\mathrm{NR}$, not reported. 
Table 2. Reported cases of pulmonary amyloidoma with associated monoclonal light chain lymphoplasmacytic reaction.

\begin{tabular}{lccccc} 
Reference & Age & Sex & Size $(\mathrm{cm})$ & Number of lesions & Light chain \\
Original case & 55 & M & 2.2 & Single & Lambda \\
Original case & 76 & M & $1.5-9.3$ & Multiple & Kappa \\
\hline Miyamoto & 72 & M & $0.9-3.5$ & Multiple & Kappa \\
Ross & 60 & F & $0.7-2$ & Multiple & NR \\
\hline Ross & 73 & F & NR & Multiple & NR \\
Ihing & 67 & M & 2.5 & Multiple & Lambda \\
\hline Ihing & 66 & M & 3 & Multiple & Lambda \\
Davis & 56 & M & 1.5 & Multiple & Kappa \\
\hline Murata & 63 & M & NR & Multiple & Kappa \\
\hline
\end{tabular}

NR, not reported.

chain restriction, and may mimic many other lesions on imaging and histology. A tissue sample consisting of amorphous eosinophilic material must be stained with Congo Red to confirm the presence of amyloid. After making the diagnosis of amyloidoma, the lesion should be stained for kappa and lambda light chains to determine clonality. Light chain restriction may represent a low-grade lymphoproliferative disorder, however associated significant systemic disease has not been reported to date. Further workup including serum and urine protein electrophoresis is necessary to avoid missing a diagnosis such as primary pulmonary lymphoma or pulmonary light chain disease which would require further treatment and is associated with worse prognosis.

The principle diagnostic concern with regards to NPA in particular is exclusion of underlying malignancy and systemic disease. Much of this diagnostic goal is derived from imaging properties of the NPA lesions. Classical NPA can be identified by characteristics including sharp lobulated contours, central or irregular calcification, single or multiple lesions of variable shapes and sizes with slow growth over years. ${ }^{18}$ As with our case report, nodules can be FDG-avid on PET scan, further increasing the suspicion for malignancy. The nodules may also display central calcification further eliciting a potentially malignant picture. Both B cell lymphoma and mucosa-associated lymphoid tissue (MALT) must be ruled out as both associations have been described in rare cases. ${ }^{19-22}$ Diagnostic uncertainty and symptoms secondary to mass effect often prompt biopsy and surgical resection of these lesions. Transbronchial or endobronchial biopsy can sometimes facilitate analysis, however thoracoscopic wedge resection or open lung biopsy are often needed for diagnosis certainty.

\section{Conclusions}

Nodular pulmonary amyloidoma with associated monoclonal plasmacytic infiltrate is a rare entity. Proper radiographic, histologic, and IHC workup can identify these lesions with particular attention to exclusion of systemic disease and associated malignancy to identify those patients who will benefit from directed treatment strategies.

\section{References}

1. Sipe JD, Benson MD, Buxbaum JN, et al. Amyloid fibril protein nomenclature: 2012 recommendations from the nomenclature committee of the international society of amyloidosis. Amyloid 2012;19:167-70.

2. Picken MM. Amyloidosis-where are we now and where are we heading? Arch Pathol Lab Med 2010;134:545-51.

3. Hui AN, Koss MN, Hochholzer L, Wehunt WD. Amyloidosis presenting in the lower respiratory tract. clinicopathologic, radiologic, immunohistochemical, and histochemical studies on 48 cases. Arch Pathol Lab Med 1986;110:212-8.

4. Grogg KL, Aubry MC, Vrana JA, et al. Nodular pulmonary amyloidosis is characterized by localized immunoglobulin deposition and is frequently associated with an indolent B-cell lymphoproliferative disorder. Am J Surg Pathol 2013;37; 406-12.

5. Thompson PJ, Citron KM. Amyloid and the lower respiratory tract. Thorax 1983;38:847.

6. da Costa P, Corrin B. Amyloidosis localized to the lower respiratory tract: probable immunoamyloid nature of the tracheobronchial and nodular pulmonary forms. Histopathology 1985;9:703-10.

7. Pitz MW, Gibson IW, Johnston JB. Isolated pulmonary amyloidosis: case report and review of the literature. Am $\mathrm{J}$ Hematol 2006;81:212-3.

8. Utz JP, Swensen SJ, Gertz MA. Pulmonary amyloidosis: the Mayo Clinic experience from 1980-1993. Ann Intern Med 1996;124:407-13.

9. Smith RR, Hutchins GM, Moore GW,
Humphrey RL. Type and distribution of pulmonary parenchymal and vascular amyloid. correlation with cardiac amyloid. Am J Med 1979;66:96-104.

10. Cordier JF, Loire R, Brune J. Amyloidosis of the lower respiratory tract. clinical and pathologic features in a series of 21 patients. Chest 1986;90:827-31.

11. Gertz M. Immunoglobulin light chain amyloidosis: 2013 update on diagnosis, prognosis, and treatment. Am J Hematol 2013;88:416-25.

12. Dacic S, Colby TV, Yousem SA. Nodular amyloidoma and primary pulmonary lymphoma with amyloid production: a differential diagnostic problem. Mod Pathol 2000;13:934-40.

13. Kawashima T, Nishimura H, Akiyama H, et al. Primary pulmonary mucosa-associated lymphoid tissue lymphoma combined with idiopathic thrombocytopenic purpura and amyloidoma in the lung. J Nippon Med Sch 2005;72:370-4.

14. Podbielski FJ, Nelson DG, Pearsall GF Jr, et al. Nodular pulmonary amyloidosis. J Thorac Cardiovasc Surg 1997;114:289-91.

15. Desai RA, Mahajan VK, Benjamin S, et al. Pulmonary amyloidoma and hilar adenopathy. rare manifestations of primary amyloidosis. Chest 1979;76:170-3.

16. Pusztaszeri M, Kamel EM, Artemisia S, et al. Nodular pseudotumoral pulmonary amyloidosis mimicking pulmonary carcinoma. Thorax 2005;60:440.

17. Asad S, Aquino SL, Piyavisetpat N, Fischman AJ. False-positive FDG positron emission tomography uptake in nonmalignant chest abnormalities. AJR Am J Roentgenol 2004;182:983-9.

18. Liu M, Wei S, Li X, et al. Pulmonary nodular amyloidosis in a patient undergoing lobectomy: a case report. J Med Case Rep 2013;7:248.

19. Miyamoto T, Kobayashi T, Makiyama M, et al. Monoclonality of infiltrating plasma cells in primary pulmonary nodular amyloidosis: Detection with polymerase chain reaction. J Clin Pathol 1999;52:464-7.

20. Ross P Jr, Magro CM. Clonal light chain restricted primary intrapulmonary nodular amyloidosis. Ann Thorac Surg 2005;80: 344-7.

21. Ihling C, Weirich G, Gaa A, Schaefer HE. Amyloid tumors of the lung-an immunocytoma? Pathol Res Pract 1996;192:446-52.

22. Davis CJ, Butchart EG, Gibbs AR. Nodular pulmonary amyloidosis occurring in association with pulmonary lymphoma. Thorax 1991;46:217-8.

23. Murata Y, Kusajima K, Ooishi F, et al. A case of extramedullary plasmacytoma of the lung associated with nodular deposit of amyloid. Nihon Kyobu Shikkan Gakkai Zasshi 1995;33:444-450. 